\title{
PIRACICABA NO SÉCULO XIX: UMA PAISAGEM EM MUDANÇA
}

\author{
PIRACICABA IN THE NINETEENTH CENTURY: A \\ LANDSCAPE IN CHANGE
}

Adalmir Leonidio*

Resumo: Busca-se com este artigo entender o processo de formação da paisagem rural de Piracicaba, cidade do interior de São Paulo que se tem destacado, desde o século XIX, por sua produção açucareira. Baseia-se em ampla e variada fonte documental - dados estatísticos, narrativas de viagem, manuais de agricultura, jornais e revistas - trabalhada de forma regressiva, isto é, a partir de fins do século XIX, quando as informações são mais abundantes e tem por hipótese principal a relação dialética entre dinâmica agrária e dinâmica de padrões paisagísticos. Insere-se em uma pesquisa mais ampla, interdisciplinar e temática, da Escola Superior de Agricultura Luiz de Queiroz.

Palavras-chave: Paisagem. Agricultura. Piracicaba.

\begin{abstract}
Search with this article understand the process of training the rural landscape of Piracicaba, town in the interior of São Paulo that has posted since the nineteenth century, by its sugar production. It is based on broad and varied documental source - statistical data, narratives of travel, manuals of agriculture, newspapers and magazines - worked in a regressive method, that is, from the late nineteenth century, when the information is more abundant and has by main hypothesis the dialectical relation between dynamic agrarian and dynamic patterns of landscape. Is part of a broader research, interdisciplinary, the Escola Superior de Agricultura Luiz de Queiroz.
\end{abstract}

Keywords: Landscape. Agriculture. Piracicaba.

* Professor associado no Departamento de Economia e Sociologia da Escola Superior de Agricultura Luiz de Queiroz (ESALQ), Universidade de São Paulo (USP). E-mail: leonidio@usp.br 


\section{INTRODUÇÃO}

No senso comum e na literatura não especializada em história predomina a ideia da existência de "áreas tradicionais" de cana e de pastagens, que supostamente estão ali do mesmo modo que sempre estiveram. ${ }^{1}$ É bem verdade que a cana é hoje uma norma que se impõe aos olhos de qualquer viajante que percorra a região de Piracicaba, realidade não muito diferente a outras regiões de São Paulo. Não é nenhuma novidade que a história do Brasil quase se confunde, em velhos manuais escolares, com a história da cana. Ora, as normas, os padrões, as formas aparentemente fixas, têm elas também a sua própria história.

Mas a despeito do que os olhos vêm e os manuais nos revelam, há um outro paradoxo que circunda passado e presente de São Paulo. O avanço dos cafezais obscureceu a memória dos canaviais. O orgulho paulista é o café. Bem como tudo que a ele esteve associado: a presença imigrante, as ferrovias, a indústria, o "espírito empreendedor" e, até, a devastação da vegetação nativa. Parece que o açúcar era mesmo algo que se devia esquecer. Ligada aos atrasados senhores nordestinos e à memória negra da escravidão, a atividade açucareira estava inscrita no ostracismo dos tempos. Mas, talvez com algum exagero da expressão, é difícil imaginar o que teria sido do café se não fosse o açúcar. De fato, em muitas áreas, foi a lavoura canavieira que permitiu à cafeicultura contar com capitais e infraestrutura necessárias à sua expansão.

Mas afinal, a despeito do que os olhos vêm e a memória institui, o que tem a nos dizer a história? O propósito deste trabalho, então, é muito simples, pensar a mudança das paisagens na imensa região de Piracicaba, entre o início de seu povoamento e fins do século XIX e mostrar que processos medeiam a memória de ontem e os padrões de hoje. Em outras palavras, qual a relação existente entre a dinâmica de uso da terra e a dinâmica de paisagem?

Os dados foram agrupados em oito tipos principais: área das propriedades, área natural, caracterização das atividades agrícolas, caracterização da paisagem, demografia, produção, técnicas e comunicações e iconografia. Compunham assim um conjunto muito variado, tanto qualitativo quanto quantitativo, oriundos de fontes as mais diversas, tais como: estatísticas oficiais, recenseamentos, narrativas de viagem, manuais de agricultura, informativos agrícolas, revistas, jornais, entre outros.

O tempo relativamente longo sobre o qual se debruça deriva de uma necessidade quase "natural". As paisagens se transformam muito lentamente. Formar séries convenientes seria quase impossível se a escala temporal fosse outra. $\mathrm{O}$ que não quer dizer que tenha sido fácil compor séries com o que se tinha em mãos. As descontinuidades eram enormes e foi preciso recorrer, muitas 
vezes, a estimativas. Neste sentido, os dados qualitativos foram de fundamental importância, uma vez que permitiram deduzir aquilo que os dados quantitativos não permitiam ver. É preciso dizer, por fim, que este artigo apresenta, de forma resumida, uma parte de pesquisa mais ampla, cujo resultado final será apresentado mais tarde, sob a forma de livro.

\section{O INÍCIO DO POVOAMENTO: O HOMEM, O MILHO E A "NATUREZA"}

Piracicaba ocupava, até meados do século XIX, uma área total de cerca de 13.000 quilômetros quadrados, quase dez vezes o seu tamanho atual. Sabe-se que a região fora habitada pelos índios Paiaguás ${ }^{2}$, uma das diversas etnias do mosaico cultural chaqueano. Eram povos caçadores nômades, pescadores e coletores, mas não praticavam a agricultura. ${ }^{3}$ Em sendo assim, pode-se supor que as áreas de vegetação natural foram muito pouco alteradas em épocas remotas pelo homem e que de fato a prática da agricultura e da destruição da cobertura vegetal original só passou a ser uma realidade em data relativamente recente, com o início do povoamento de Piracicaba. Suas alterações anteriores devem-se a mudanças decorrentes da dinâmica natural e própria aos ecossistemas.

No século XVIII, um termo da Vila de Itu, pertencente à província de São Paulo, era considerada "boca de sertão", caminho para Mato Grosso, para aqueles em busca de ouro. Este caminho atravessava o rio Piracicaba, logo abaixo das corredeiras do salto de mesmo nome. Rio abundante em peixes, cercado de matas abundantes em caça. As datas são pouco precisas. O Almanack de Piracicaba para 1900 informa que Pedro de Moraes Cavalcanti requereu, em 1693, uma sesmaria abrangendo os dois lados do rio Piracicaba. Sabe-se também que Felipe Cardoso obteve, em 1723, uma sesmaria que circundava o porto do rio, nas proximidades do Salto. Fundamental neste sentido foi a decisão do governador da capitania de São Paulo, D. Luiz Antonio de Souza Botelho Mourão, de doar sesmarias e intensificar o processo de povoamento, a fim de servir de fonte de víveres para a recém-criada colônia de Iguatemi. ${ }^{4}$

A povoação foi fundada oficialmente no dia primeiro de agosto de 1767, mas, por esta data, nela já haviam ranchos e roçados estabelecidos, graças ao picadão aberto por Felipe Cardoso, que ligava Itu ao Salto do Rio. ${ }^{5}$ Assim, o povoamento inicial seguia o curso do rio, nos vales, sempre nos vales. Só muito depois é que os planaltos seriam ocupados. $\mathrm{O}$ transporte por terra era sempre muito difícil. Era demorado e sujeito a muitas perdas e riscos. Caminhos lamacentos, matas sombrias, já sem o risco dos ataques de índios, mas não de eventuais bandidos. A ferrovia seria um artifício muito tardio, de fins do século XIX. 
A partir de 1774, a povoação foi elevada a freguesia e novas sesmarias foram sendo concedidas desde então. O viajante e geógrafo Lacerda de Almeida (1753-1798) observou, em 1788, uma porção de sítios, em ambas as margens do rio Piracicaba, cujos moradores se agrupavam nos pátios das casas para verem passar as canoas de sua expedição. Por esta época, de acordo com um recenseamento da capitania de São Paulo, ainda não se plantava cana em Piracicaba, apenas milho, feijão, arroz e algodão, num total de 45 unidades e 231 pessoas. ${ }^{6}$ Mas já em 1799 podia-se contar 9 engenhos em funcionamento, com uma produção total de 1922 arrobas de açúcar. Contudo, alguns anos depois, em 1816, a população salta para 2.250 pessoas e o número de engenhos quase duplica. Apesar desta expansão relativa da cana, o milho ainda se impõe à paisagem rural. Somente em 1828 a cana o ultrapassaria em importância. Ainda assim, ele se espalhava como uma mancha verde por cerca $89 \mathrm{mil}$ alqueires de terra. ${ }^{7}$

Com uma população tão dispersa como a que se observa em fins do século XVIII, é difícil imaginar que a pressão sobre a terra fosse fator de relevo neste momento. Não há dados específicos sobre o problema, mas é possível conjecturar que um sistema de cultivo baseado em pousio longo ou florestal fosse de fato o mais usual entre os roceiros da região. Assim, clareiras eram abertas anualmente nas florestas e semeadas ou plantadas por cerca de dois anos consecutivos. Em seguida, eram abandonadas durante um período longo o suficiente para que a floresta as invadisse outra vez, algo em torno de 10 a 20 anos.

É interessante notar que Piracicaba começou a ser povoada num momento em que novas normas limitavam o tamanho das sesmarias, e isso deveria limitar bastante também o tempo de pousio. Não tendo uma área vasta para a prática da rotação florestal, é possível que o pousio tenha tendido a se encurtar um pouco mais. Neste contexto, talvez seja mais realista falar-se em um pousio do tipo arbustivo, com a terra ficando em descanso por cerca de seis a dez anos, algo insuficiente para haver a recuperação florestal, mas suficiente para a recuperação da fertilidade do solo.

A provisão de 19 de maio de 1729 limitou as novas concessões de terras a três léguas de comprimento e uma de largura ou três de largura e uma de comprimento (cerca de 7.000 hectares). Apesar de em todo o Brasil esta nova norma não ter sido respeitada, o fato é que as poucas sesmarias de que se tem notícias no "sertão de Piracicaba", 17 ao todo, concedidas no século XVIII, parecem não ultrapassar estas dimensões. ${ }^{8}$

Apesar das dificuldades da lei e da presença contínua de pequenos posseiros parecia predominar por esta época, na paisagem agrária da região, a grande propriedade. Mas só muito raramente as fazendas ultrapassavam os 16 mil alqueires, como no caso Vergueiro, mormente na região de Araraquara, domínio das fazendas de criar e dos infindáveis campos e matas. Em sendo 
assim, não se pode comparar o povoamento e a ocupação de Piracicaba com a colonização do litoral ou das áreas prósperas do café no Vale do Paraíba, inserida nos marcos comerciais da grande lavoura. Ao lado das sesmarias mais modestas, muitos sítios, posses e, sobretudo, terras devolutas à espera do homem. Além disso, a própria estrutura populacional parece sugerir isso. Um tombamento feito em 1817 apontava um total de 264 lavradores na região, para uma população que beirava os dois mil habitantes. Número relativamente elevado, se comparado ao total de apenas 893 escravos. ${ }^{9}$ A cana ainda não havia imposto sua marca indelével sobre a paisagem, ainda relativamente pouco humanizada.

Mas a despeito do suposto "caráter florestal" da Piracicaba primitiva ${ }^{10}$, muitos foram os naturalistas do século XIX que tentaram ver as coisas com outros olhos, e viram coisas bem diferentes. Auguste de Saint-Hilaire, o mais notável entre eles, preferiu olhar não para a vegetação em si, mas para a topografia. E aí viu longas planícies onduladas, e no meio de gramíneas rasteiras, numerosos mas pouco extensos grupos de árvores, "muito próximas umas das outras, formando uma espécie de mosaico em dois tons de verde muito diferentes". Depois concluiu:

Não podemos deixar de conjecturar se esses grupos de árvores não constituem os restos da floresta que começa nas proximidades de Moji-Mirim, e se essa região não teria sido outrora coberta de matas até São Paulo. A natureza da vegetação poderia levar-nos a pensar assim, mas a topografia do terreno e a totalidade dos dados históricos refutam essa hipótese. ${ }^{11}$

Assim, as descrições de alguns viajantes do início do século XIX dão conta de que a região teria como matriz paisagística vastas áreas de "matas", mas pontilhadas por campos em diversos estágios de sucessão - "campo cerrado", "campo limpo", "cerradão", “capoeira de mata virgem"... conforme denominações da época -, bem como por culturas de diversos tipos: milho, muito milho, feijão, mandioca, cana... Contudo, é interessante notar que o botânico Lund observou, para a segunda metade do século, que a "Catanduva" 12 era a "mata virgem dos planaltos", estando distribuída por "poucas léguas, em terrenos chatos ou de ondulações suaves", enquanto os "campos cerrados têm uma distribuição incomparavelmente maior do que a Catanduva". ${ }^{13} \mathrm{O}$ mesmo parece atestar os Relatos monçoeiros. Segundo um dos sertanistas que percorreram a região, "em distância de dez léguas no rumo Leste... quase tudo Campanha, porém agreste e com pouco préstimo". ${ }^{14}$

Apesar das especulações de Saint-Hilaire e Lund, é pouco provável que as áreas de cerrado e de campo, que ocupavam vastas porções de terra na região, tenham origem recente, em função do fogo ateado às matas. Isto 
porque, como dito, apesar da intensidade das atividades de caça dos paiaguás, antigos habitantes das matas, a agricultura não era praticada na região antes da chegada dos colonizadores, em fins do século XVIII. Devido à baixa densidade demográfica predominante até o início do século XIX, é pouco provável que um sistema de cultivo baseado no pousio longo tenha determinado o tipo de paisagem de campos que nossos cronistas descrevem.

Assim, é pouco provável que num espaço de tempo tão curto, entre fins do século XVIII e meados do século XIX, a vegetação do tipo "Catanduva", encontrada, sobretudo, nos vales, tenha sido transformada em cerrados e campos limpos, graças à ação continuada da agricultura de coivara, comum tanto às grandes quanto às pequenas lavouras. Sobretudo porque, neste curto espaço de tempo, apesar da baixa densidade demográfica, os dados apontam para uma tendência de uso do pousio curto, principalmente nas lavouras comerciais de cana. Em outras palavras, a dinâmica sugerida entre encurtamento do pousio, recuo da floresta e surgimento de campos cerrados só será válida num tempo muito mais longo do que aquele com o qual estamos a trabalhar.

Em sendo assim, fica por precisar a origem dos campos em Piracicaba. O que se sabe é que eles eram um componente iniludível da paisagem natural e que vão ser incorporados à dinâmica agrária, não só em função do pastoreio, como também da agricultura. Embora os dados quantitativos trabalhados ainda não permitam dimensionar bem o problema, é possível, contudo, conjecturar que as áreas de campo eram bem maiores já no início do século XIX. ${ }^{15}$

Reforça este argumento o predomínio de solos de tipo arenoso na maior parte da região. Se a presença da lavoura por si só já é um indicador da presença anterior de floresta, deve-se notar, todavia, que esta dinâmica irá mudar na segunda metade do século XIX, quando os solos mais férteis se esgotam e não resta outra alternativa aos agricultores senão ocupar as áreas antes desprezadas de campos. Em sendo assim, um modelo aceitável de ocupação e uso do solo por nossos primeiros povoadores, associado ao esquema de sucessão ecológica que vem de tempos anteriores, pode então ser o seguinte: 


\section{Figura 1: Fluxograma do processo de ocupação das terras pela agricultura}

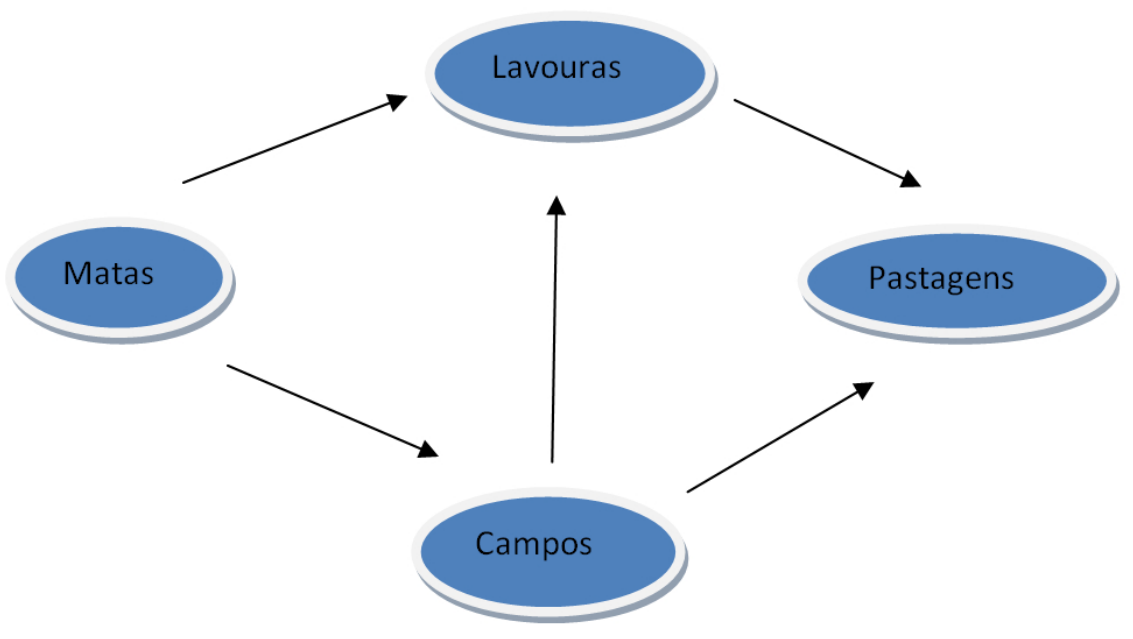

Fonte: Criação do autor.

Obviamente, não se trata de um modelo fixo, pois, como dito, as áreas de cerrado em fins do século XIX já quase não existiam. Ele será alterado em conformidade com as mudanças que irão ocorrer na estrutura populacional, bem como com os padrões técnicos em uso. Isto é, no momento em que a fronteira agrícola se fecha e não há mais áreas de mata a serem incorporadas à agricultura, os agricultores se vêm forçados a ocupar áreas menos férteis, como as de campo, antes desprezadas. Do mesmo modo, se vêm forçados a encurtar o tempo de pousio, mormente na medida em que a escravidão chega ao fim. ${ }^{16}$ Mas incorporar áreas de campo à agricultura pressupõe um uso bem mais racional das técnicas agrícolas, além do fogo e do machado. Daí porque, nos principais jornais e revistas de Piracicaba, serão cada vez mais comuns a propaganda de arados e outros implementos.

Como dito, tanto os campos naturais, quanto as capoeiras eram comumente usados como pastagem. Araraquara, apesar de "quase toda cercada de matas"17, possuía extensas áreas de campos, "onde os capões se multiplicam". ${ }^{18}$ Em 1828, toda a região de Piracicaba, mas com destaque para Araraquara, produziu ao todo 10.029 cabeças de gado e 7.237 de porco. Como veremos, a tendência será de os porcos ultrapassarem, e muito, os bois. Isto indica já uma tendência, a de as unidades menores dominarem a paisagem local.

Deve-se observar que mesmo áreas antigas de lavoura, do início do povoamento, isso por volta de 1767, encontravam-se completamente abandonadas no início do século, e onde o mato voltava a crescer, dando a impressão aos viajantes de tratar-se de antigas áreas de mata. É o que nos sugere as descrições de Hércules Florence, naturalista da expedição do Barão 
de Langsdorff, entre 1826 e $1827 .{ }^{19}$ E é o mesmo Florence quem nos dá a melhor imagem do que seria a paisagem de Piracicaba por esta época, bem menos monótona, bem menos humana:

O olhar não se cansa de admirar as cores várias que de todos os lados a embelezam: aqui é uma verdejante várzea; ali fica o cerrado com suas árvores baixinhas e engrovinhadas; adiante se alarga um campo de macega mais alta que um homem e de um colorido puxando a amarelo pardacento. Muitas vezes grandes áreas de terreno, colinas inteiras, apresentam um aspecto sombrio e negrejante: é que por ali passou uma chama devoradora, ateada pelo viajante. ${ }^{20}$

No fim do século XIX, quando os planaltos começarem a ser ocupados pelo café, já não haverá qualquer vestígio das antigas áreas de várzea. A mesma tendência será seguida pelo cerrado. O fogo terá destruído a todas. Esta visão deslumbrada pelo viajante era muito comum no Brasil, desde os tempos coloniais, com a introdução da cultura canavieira. Prática adquirida dos indígenas, a coivara, isto é, a queima inicial da mata de forma a desbastar o terreno antes do plantio, impôs-se como artifício primordial entre nossos primeiros colonos, e assim se perpetuou ao longo dos anos, como uma força da natureza.

\section{A CANA DE AÇÚCAR: UM SISTEMA DE GRANDE LAVOURA?}

Como é de conhecimento geral, o Brasil nasceu com o açúcar. ${ }^{21} \mathrm{Ou}$ melhor, como diria um historiador já clássico ${ }^{22}$, o Brasil nasceu para fornecer certos produtos altamente valorizados à economia mundial em formação. $\mathrm{E}$ este produto foi, por muito tempo, o açúcar extraído da cana. O modelo usado, a fim de atender a estes objetivos puramente mercantis, todos o sabem, foi o latifúndio monocultor e escravista.

As monoculturas impostas em todas as colônias tropicais do Novo Mundo tiveram um efeito devastador sobre sua ecologia e população. Dizimaram os nativos da terra, com doenças e trabalhos forçados, e de quebra introduziram milhares de europeus e africanos com hábitos radicalmente diferentes dos vossos. Por outro lado, introduziram centenas de espécies novas, animais ou vegetais, em seus ecossistemas.

Mas o que de fato serviu para remodelar toda a dinâmica existente entre o homem e a terra foi a forma de trabalho adotada e a mentalidade que lhe correspondia. Como mostrou em diferentes ocasiões Sérgio Buarque de Holanda, a natureza não se constituiu, entre nossos primeiros colonizadores, em um obstáculo a ser superado, mediante o trabalho incorporado e o avanço das 
forças produtivas, mas em um bem a ser desfrutado passivamente. Demandava aventura e não trabalho. Daí a forma como a agricultura se organizou, com desleixo e abandono. ${ }^{23}$

Contudo, o trabalho pouco produtivo dos escravos era compensado pela produção massiva de um único produto. Por isso, era preciso muita terra disponível e barata, bem como vasta oferta de mão-de-obra. A primeira foi conseguida, quase gratuitamente, pela instituição das sesmarias; e a segunda, pelo rendoso mercado escravista africano. Não era necessário adquirir sementes para plantio, tão pouco qualquer outra forma de insumo para melhorar a fertilidade da terra. Terras férteis havia aos montes, de forma quase inesgotável. Para incorporá-las ao processo produtivo, bastava derrubar a mata virgem que lhe povoava a superfície. E para isso, havia um instrumento quase gratuito, mas perfeito, conhecido do homem à milhares e milhares de anos, o fogo.

Um engenho para funcionar precisava de animais de tração, água corrente e madeira, tanto para as caldeiras como para as necessidades de construção ordinárias. ${ }^{24}$ Por isso mesmo, toda unidade produtora de açúcar, além das vastas áreas com cana, necessitava igualmente de muita mata próxima, bem como de significativas áreas de pasto. Completando esta paisagem peculiar do Brasil açucareiro, tínhamos muitas roças de mantimentos, cultivadas por escravos em suas horas de "folga", mas que eram de fundamental importância para a manutenção do engenho e sua engrenagem produtiva.

Em sendo assim, a paisagem da grande lavoura no Brasil, aquela existente no Nordeste açucareiro, tinha sua dinâmica dominada pelo crescimento em extensão: à medida que as condições do mercado eram favoráveis e os fatores internos não eram limitativos, a monocultura se expandia ocupando novas áreas. Havendo restrição do lado da demanda, ou limitações de ordem interna, ela se retraía e com isso muitas áreas de lavoura podiam tornar-se decadentes, voltando a ser ocupadas por mato. Eram os engenhos de fogo morto.

No final do século XVII a economia açucareira estagnou-se e até regrediu em algumas regiões do país, em virtude, sobretudo, da descoberta de ouro em Minas Gerais e da concorrência das colônias inglesas e francesas das Antilhas, com seu açúcar mais barato e de melhor qualidade. Além disso, as terras se esgotavam e ficava cada vez mais difícil ocupar áreas novas com o fechamento da fronteira agrícola. Ainda assim, pouco se fez para reverter a situação. ${ }^{25}$

Com o declínio da mineração, a agricultura volta a ocupar lugar de destaque na economia colonial. Um dos indicadores desta lenta e contínua recuperação pode ser visto nas importações de escravos, que voltaram a crescer no final do século XVIII. Entre as características marcantes desta recuperação podemos destacar três principais: diversificação da pauta de exportações, interiorização da economia e intensificação da relação com o mercado interno. 
E é precisamente este o tempo do açúcar em São Paulo. A cana foi introduzida no estado no final do século XVIII ${ }^{26}$, quando suas áreas mais tradicionais já haviam entrado em declínio quase irreversível. Introduzida inicialmente no litoral Norte do estado, foi depois transferida para o planalto, onde as condições mesológicas eram melhores. Já em fins do século XVIII a produção de açúcar era expressiva na região de Itu. Mas à medida que a fronteira agrícola ia se fechando em Itu, novos empreendedores deslocavamse para as regiões vizinhas, como Porto Feliz, que em fins do século XVIII contava 46 engenhos. Daí partiria para as terras do chamado "quadrilátero do açúcar", Jundiaí, Mogi Guaçu, Piracicaba e Sorocaba, onde conheceria sua mais significativa experiência. ${ }^{27}$

Obviamente, a situação do açúcar no planalto era bem diferente daquela encontrada no Litoral. Primeiro porque as distâncias até os portos de exportação, inicialmente o do Rio de Janeiro e, depois, o de Santos, eram enormes. E as condições de transporte, como dito, eram para lá de precárias. Em 1836, Domingos Braga e Teodoro Zeferino dirigem ao presidente de província uma proposta de abertura de uma nova estrada, que iria encurtar em 130 léguas (cerca de $628 \mathrm{~km}$ ) a distância de São Paulo a Mato Grosso. Essa estrada partiria de Araraquara e "sobre um leito por entre campos e campestres atravessava o Rio Grande abaixo do porto hoje denominado São Francisco de Sales". ${ }^{28}$ Assim, em 1839, havia duas estradas abertas. Mas apesar disso, o isolamento de Piracicaba era um fato que só começaria a ser superado na segunda metade do século XIX, com a expansão ferroviária. Com isso, os custos de produção deveriam subir muito além do esperado para os negócios do açúcar.

Mas, se os custos eram altos, afinal, de onde vinham os capitais investidos no açúcar? Conjectura-se que tenham vindo das pequenas roças e dos pequenos engenhos e engenhocas, que gradativamente foram sendo instalados. Daí a importância do povoamento inicial, com base no cultivo de alimentos. Mas os engenhos maiores, muitos destes vieram de fora, como os do Senador Vergueiro. ${ }^{29}$ Acrescenta-se a estas dificuldades o fato de que, no início do século XIX, a oferta de mão-de-obra escrava era cada vez mais escassa, tornando ainda mais oneroso o processo produtivo.

Neste sentido, uma fronteira ambiental aberta, com grande estoque de terras férteis, matas para fornecimento de lenha e vastas áreas de campos naturais para pastagem dos animais era vital para o negócio do açúcar na região. Ainda mais quando o volume da produção não tendia a compensar a baixa rentabilidade do trabalho. A população escrava continuou a crescer em todo o período em ritmo muito mais acentuado que a população livre. E em 1836 ela era mais de $50 \%$ da população de Piracicaba, apesar de diminuir bastante depois de $1850 .^{30}$

E o ritmo das mudanças técnicas tendeu, em geral, a acompanhar este padrão demográfico da região. No final do século XIX, Júlio Brandão Sobrinho, 
em seu Almanaque ilustrado do lavrador paulista, se queixava da "velha e condenável rotina", comum entre agricultores de São Paulo. Preparavam mal o terreno, com uso apenas da enxada; não estrumavam as covas abertas, apesar da abundância de estrume; dispensavam 3 a 4 capinas anuais, para manter o terreno livre de ervas daninhas e nada mais. E se admirava de, "ainda assim", os canaviais produzirem "admiravelmente", por até vinte anos seguidos. No fim de 12 a 14 meses a cana era colhida e levada para moagem. Com isso, um canavial produzia na época, em média, 100 arrobas por alqueire (cerca de $620 \mathrm{~kg}$ por hectare), para cada escravo utilizado. Isso equivalia a cerca de três arrobas de açúcar bruto, pronto para ser exportado. Pela mesma época, nos Estados Unidos e nas Antilhas a produtividade média era de 400 arrobas de cana e 8 arrobas de açúcar. Para se ter uma ideia, a produtividade brasileira da época corresponde a menos de $1 \%$ do rendimento atual, que é de 70 toneladas por hectare. ${ }^{31}$

Nas condições do litoral nordestino isso não era propriamente um problema, uma vez que o número de escravos empregado era bastante elevado. Contudo, em Piracicaba, o padrão era outro, apesar do número elevado de escravos em relação à população total. O número médio de escravos encontrado, no caso dos engenhos maiores, era de 50 , podendo chegar a 4 ou 5 nos menores, muito longe dos 200, 300 e até 500 escravos do Nordeste. Nestas condições, a produção de açúcar piracicabano chegou a 92.439 arrobas em 1828, subindo para 160.000 arrobas, em 1854. O que corresponde a, aproximadamente, 2.237 hectares, em 1828, e 3.872 hectares, em 1854, de cana plantada na região. Mas para se ter uma visão mais realista do problema, é preciso primeiro olharmos para as áreas ocupadas pelas propriedades rurais em Piracicaba.

Ora, os dados mostram claramente ${ }^{32}$ que as áreas das médias e grandes propriedades, em geral aquelas ocupadas com cana, eram bem superiores àquelas efetivamente ocupadas com a gramínea. Isto nos revela que as áreas destinadas à cana eram subutilizadas. Isto porque, como dito, havia sempre que se ter grandes áreas da propriedade reservadas não apenas para o fornecimento de lenha e pasto, como também para futuras expansões da cultura. Assim, por um lado, se o modelo extensivo atrasou em décadas a produtividade média do trabalho na região, postergou um pouco a devastação das áreas com cobertura vegetal original. A necessidade constante de madeira funcionou como uma espécie de "código florestal" primitivo, apesar do espectro assombroso, sempre a rondar o senhor de engenho, dos engenhos de "fogo morto".

Mas o que quer dizer precisamente "postergou um pouco"? Sabe-se que as áreas de mata virgem eram cultivadas por cerca de 3 a 4 anos seguidos com cana. Seguia-se um tempo de pousio que durava em média 4 ou 5 anos. Neste tempo, a capoeira crescia e o solo se recuperava. Enquanto isso, áreas novas iam sendo ocupadas, até serem também abandonadas. ${ }^{33}$ Mas, como dito, uma área de cana durava em média 20 anos, até ser abandonada definitivamente e 
tornar-se área de campo ou capoeira. Isso quer dizer que o seu tempo efetivo de uso com cana era bem pequeno. Mas sabe-se também que uma área que havia sido ocupada com cana não era abandonada em definitivo, sobretudo quando a fronteira agrícola se fecha. Ela podia ser usada para pastagem ou por pequenos roceiros para cultivarem seus alimentos.

Pelos dados disponíveis ${ }^{34}$, vê-se claramente que a fronteira agrícola avança consideravelmente ao longo da primeira metade do século XIX. Tanto as grandes quanto as médias e pequenas propriedades aumentam em número e tamanho, apesar do predomínio incontestável da primeira na paisagem piracicabana. Predomínio que não quer dizer, como mostramos, que a matriz paisagística fosse já nessa época de cana. Aliás, estava longe disso. Primeiro, porque havia ainda enormes áreas de mata nativa, tanto dentro quanto fora das propriedades. Depois, porque Piracicaba era muito mais do que cana.

Em outras palavras, a diversidade era enorme. O açúcar aumentou consideravelmente sua produção, graças ao aumento do número de engenhos instalados na região. Mas as culturas alimentares também acompanharam este ritmo de crescimento, assim como a criação de animais, graças à enorme disponibilidade de pastos naturais. Entre 1864 e 1866 houve um enorme salto na produção de algodão, em função da guerra civil americana. Depois de 1867 o algodão quase desaparece. Mas o que mais chama a atenção é a área ocupada pelo milho, muito superior à do açúcar. Isto se explica porque o milho não era plantado apenas por pequenos roceiros, mas por toda sorte de gente, inclusive pelos donos de engenho e plantadores de cana. De modo que o milho ocupava nesta época um lugar especial na paisagem piracicabana, apesar de ir diminuindo ano a ano, como veremos.

Esse encolhimento da paisagem do milho ao longo do século XIX tem duas explicações possíveis. Primeiro e acima de tudo, é provável que suas áreas tenham vindo a ser ocupadas por cana e, posteriormente, café, na medida em que a fronteira agrícola ia se fechando. Pedro Müller afirma que, em 1836, não há mais terras devolutas em Piracicaba. Em sendo assim, as novas ocupações, por conta da expansão do plantio de cana, se darão às custas das propriedades já existentes e não sobre áreas novas. Muitas destas áreas eram aquelas de matas reservadas para isso no interior das grandes fazendas. Mas muitas se devem às pequenas e médias unidades em apuros financeiros.

Depois, o naturalista Johann E. Pohl relata que a cultura do milho apenas dava boas safras nos primeiros anos de cultivo e, em geral, após cinco anos consecutivos de cultivo o solo encontrava-se esgotado e contaminado pelo capim catingueiro ou gordura. ${ }^{35}$ Depois disso, a área precisava ficar em repouso por até cinco anos seguidos. Depois de algum tempo, como acontecia com a cana, o terreno encontrava-se bastante empobrecido para o cultivo. No caso dos pequenos roceiros, isto devia significar um terrível golpe em sua renda familiar. Daí, eram dois os caminhos possíveis, desfazer-se da área, que já não 
valia quase nada, ou tentar a sorte com outra cultura, em geral a mandioca, que conseguia resistir por mais anos seguidos em condições edáficas tão precárias.

Uma outra forma muito comum de contornar o problema entre plantadores de milho, era dividir a propriedade em talhões, cultivados por um ou dois anos no máximo. Isso devia aumentar consideravelmente a vida útil do terreno. Contudo, deve-se observar que os lavradores mais pobres tendiam a dar às suas terras um tempo menor de repouso. Os muito pobres chegavam mesmo a não dar repouso algum, como notou Saint-Hilaire. Esta situação aumentava ainda mais a pressão sobre as terras cultiváveis, bem como a vulnerabilidade social destes roceiros.

Apesar disso, o que se observa não é um processo de concentração das terras de Piracicaba, mas, ao contrário, um retalhamento das grandes unidades. Além do fechamento da fronteira, Maria Celestina Torres chama a atenção para a dissolução, em 1825, da sociedade Vergueiro \& Souza, que chegou a concentrar grandes porções de terras na região. Aos poucos, grandes propriedades como Limoeiro, Taquaral, Monte Alegre, Monjolinho, Morro Azul, Pau Queimado, vão se tornando centenas de outras propriedades. ${ }^{36}$ Acompanhado pelo aumento da população, este processo significou enorme pressão sobre as áreas ainda não cultivadas no interior das unidades maiores que se vão fracionando. Isto é, foi só a partir da segunda metade do século XIX que as áreas de vegetação original começaram a se reduzir de forma significativa. As propriedades vão se tornando não apenas mais divididas, mas também mais cultivadas, à medida que o século XIX avança.

\section{O AVANÇO DO CAFÉ, O RECUO DA CANA E A DIVERSIFICAÇÃO DA ECONOMIA PIRACICABANA}

A partir de meados do século XIX Piracicaba vê sua paisagem rural profundamente alterada. Isto se deu não apenas em função de um processo que se vinha desenhando desde a primeira metade do século, com o retalhamento das grandes unidades, como também pelo surgimento de elementos novos e de uma nova dinâmica agrária. Primeiramente, o avanço do café é incontestável. De 13 arrobas em 1828, saltou para 147.000 em $1896 .{ }^{37}$

Desde o fim do século XVIII que o café já havia sido introduzido em Jundiaí e desde a década de 1810 que se faziam experiências de adaptação da planta em terras vizinhas a Campinas. Mas somente após 1850 que o Oeste paulista conheceu sua experiência mais significativa com a cultura, tendo sido Campinas o mais importante centro cafeeiro da região e de onde partiu sua irradiação para as demais regiões da província: Itu, Rio Claro, Piracicaba... Progredia, assim, rapidamente, a substituição dos antigos engenhos pelas lavouras de café. 
Como dito anteriormente, na primeira metade do século XIX quase não se plantava café em Piracicaba. De acordo com o recenseamento de 1835, apenas os distritos de Piracicaba, Santa Bárbara, Rio Claro e Limeira, com destaque para os dois últimos, cultivavam a rubiácea. ${ }^{38}$ Mas na segunda metade, tudo muda. Apesar da queda acentuada em 1887, há uma nítida tendência de crescimento da produção cafeeira, que se alastra pela paisagem. ${ }^{39}$ Mas esta tendência não será uniforme para toda a imensa região de Piracicaba, uma vez que com os desmembramentos que irão se suceder, Piracicaba perderá muitas áreas com forte potencial cafeeiro, como Limeira e Rio Claro, em 1842.

A tendência é que as áreas de povoamento mais recente sejam aquelas ocupadas pelo café. Em alguns casos, as fazendas de café ocuparão antigas plantações de cana, mas no geral elas tenderiam a ocupar áreas antes subocupadas ou mesmo desprezadas pela cana, como os espigões, por terem estes condições mesológicas mais favoráveis ao seu cultivo. Mas a ocupação dos espigões só se tornou possível também porque o rio já não era, na segunda metade do século XIX, o meio prioritário de transporte.

Ora, muitos autores argumentaram que a melhoria nas condições de transporte tornou mais efetivo o povoamento da região. De fato, o crescimento demográfico do período é muito superior ao do período anterior. E isto se deve, sem dúvida, à vinda de imigrantes. Mas deve-se notar que, apesar de em ritmo bem menor, a população escrava continuou a subir até às vésperas da abolição. ${ }^{40}$

Isso mostra que, apesar das inovações, a produtividade do trabalho com o café continuava muito baixa. Em média, para cada escravo, cuidando de um hectare, o cafezal produzia 1.450 quilos de café, contra 3.250 quilos atuais. E isso se explica por uma série de razões. Diferentemente da cana, o cafeeiro só começa a produzir no quarto ou quinto ano. A partir do sexto chega à sua máxima performance, e depois do décimo ou décimo segundo ano começa a declinar. Em algumas regiões, em função da fertilidade do solo, o declínio da produção só se inicia a partir do vigésimo ano. ${ }^{41} \mathrm{Em}$ sendo assim, todo cafezal compunha-se de três zonas bem características, uma nova, com os pés de café que ainda não entraram em produção; uma em plena produção, entre os seis e os vinte anos; e outra decadente, onde o cafezal deixou de produzir. Não contando com a estrutura pesada dos engenhos, os cafezais eram muito mais móveis, de modo que estas zonas ou faixas iam avançando sobre áreas novas e deixando para trás áreas completamente destruídas ou estéreis.

Um fator que muito contribuía para este alto grau de mobilidade do café era a forma como ele era plantado, "em fileiras perpendiculares à base da montanha". Para Taunay, "essa ordem não só é agradável à vista, senão que favorece também a colheita. O preto vai seguindo as fileiras sem jamais se enganar". ${ }^{42}$ Mas alguns historiadores argumentam que este modo de cultivar estava relacionado à facilidade em se vigiar o escravo. ${ }^{43}$ Seja como for, o fato é que ela aumentava enormemente a erosão dos solos e com isso a sua decadência. 
Assim, se é verdade que o café formou cidades, como Jaú (1858), Ribeirão Preto (1870), Barretos (1874), entre outras, também nutriu pastagens mofinas e solos áridos. Aí, conforme referiu Monteiro Lobato, vegetavam as "cidades mortas", exauridas de seu potencial humano e de seus recursos naturais. O mesmo Taunay chegou a sugerir em seu manual um método diferente de cultivo aos agricultores brasileiros, próximo ao modelo moderno por curvas de nível. ${ }^{44}$

Tendia a diminuir o efeito da erosão o hábito de conservar as matas nos cumes dos outeiros, uma vez que elas seguravam um pouco a força da água que descia. Nos tempos de seca, elas favoreciam também os cafezais mais próximos com sua maior umidade. Hábito que ainda se mantém, por força da lei, dando um ar muito típico às paisagens rurais de São Paulo. No mais, nada mudava a rotina colonial dos plantadores de cana. Somente na década de 1870, quando pressionados pelo elevado custo da mão-de-obra escrava, pelos elevados salários dos trabalhadores livres e pelo esgotamento das terras virgens disponíveis é que os agricultores brasileiros dispuseram-se a modernizar suas técnicas de trabalho. Ainda assim, grande parte das inovações ficou, inicialmente, por conta do beneficiamento do café.

Apesar de muitos manuais de agricultura do século XIX referiremse ao café como uma cultura "exclusiva", não admitindo outra cultura em sua vizinhança, na maioria dos cafezais, mormente em sua "zona nova" ou pioneira, era prática o cultivo de alimentos entre suas fileiras. Com a introdução do trabalho imigrante, sob a forma da parceria, esta foi uma das importantes formas de remuneração do trabalho, uma vez que as famílias cultivavam aí toda sorte de alimentos para seu sustento. Isto certamente favoreceu o aumento das áreas cultivadas com arroz, feijão e, sobretudo, milho, contribuindo para uma maior diversificação da paisagem rural de Piracicaba.

Além disso, não se deve esquecer, como alguns autores têm argumentado, que o café não substituiu a cana em Piracicaba, como fez em outras regiões, como Campinas, ou até mesmo Rio Claro, que já não pertencia a Piracicaba. ${ }^{45}$ Os dados mostram que entre 1854 e 1887 houve uma tendência de queda do açúcar, embora não muito acentuada. Mas em 1896 ele voltou a crescer. Além disso, em alguns períodos, como 1857 e 1887, ele chegou a ter uma produção superior à do próprio café. ${ }^{46}$

Assim, ao lado do "complexo canavieiro" desenvolve-se e expande-se um "complexo cafeeiro", em especial entre 1850 e 1880. O fato deve-se, em parte, à proibição do tráfico negreiro em meados do século XIX e mormente ao fim da escravidão em 1888, que teve como efeito principal a crescente expansão da mão-de-obra livre, constituindo-se, assim, um mercado consumidor em potencial, baseado na demanda por bens de consumo, como açúcar e aguardente. Portanto, a produção destes bens no interior paulista e principalmente em Piracicaba, continuou a existir na passagem do século XIX para o XX. Outro fator importante da insistência na produção açucareira residia no fato de que 
o café enfrentava uma estrutura de produção recente, tornando a produção de cana preferível à do café.

Se a paisagem da cana estava fadada a desaparecer da memória da região, talvez por sua fraca inserção no mercado internacional ou pela memória do café, mais europeu, mais "progressista", o fato é que ela foi sempre uma realidade, maior ou menor, mas sempre uma realidade presente. Assim como dividia espaço com a cana, contrariamente a outras regiões, como a vizinha Campinas, a produção cafeeira também não foi tão especializada. Os dados existentes dão conta de que muitas fazendas produziam simultaneamente açúcar e café, apesar do nítido predomínio das fazendas que só produziam café. Até mesmo fazendas de algodão produziam açúcar e café, apesar de em quantidades bem modestas.

O algodão, ao lado do açúcar e do café contribuiu significativamente para a formação e a consolidação da economia piracicabana. Ao longo do século XIX, o algodão perdeu mercado no cenário mundial, fazendo com que a produção do algodão local diminuísse. Com isso, houve também uma maior dedicação ao mercado doméstico, como por exemplo, para confecção de vestimentas. Nas regiões produtoras de café, o algodão tinha outro destino: confecção de sacos para armazenar o café que seria exportado. Portanto, o desenvolvimento da produção cafeeira colaborou para o desenvolvimento de outros setores, como por exemplo, a produção de algodão, que, graças ao café, não sofreu um impacto ainda maior, devido à crise de exportação.

A esta estrutura pouco especializada da grande lavoura em Piracicaba, correspondeu um avanço significativo da produção de alimentos na segunda metade do século XIX, em grande parte voltada para o abastecimento do mercado interno e não para subsistência, como na primeira metade do século. Segundo Manoel de Morais Barros, a produção de alimentos excedia "muito o consumo local", sendo exportado para São Paulo, Itu, Campinas e Rio Claro. E com certo exagero, concluía: "Corram mais algumas dezenas de anos e Piracicaba será o celeiro da vizinhança, exceção feita a Capivari". ${ }^{47}$

No fim do século XIX houve avanço considerável das áreas de cana. Mas esse avanço não significou um recuo das lavouras de alimentos. $\mathrm{O}$ café continuava voltado prioritariamente para o mercado externo e o açúcar, aguardente e outros bens, tendiam a ocupar um espaço considerável no mercado interno. Além desses, produtos alimentícios básicos como milho, arroz, feijão e fumo aparecem como destaque na produção doméstica - estimulados pelo crescimento demográfico - e eram comercializados nos aglomerados comerciais das vilas dos imigrantes e no centro da cidade.

Esta estrutura mais diversificada imprimiu uma dinâmica nova no processo de ocupação do espaço. Os espigões foram quase todos ocupados às custas da vegetação original remanescente em áreas públicas, isto é, fora das propriedades. Mas muitas áreas antigas de cana, já em processo de sucessão 
avançada, foram sendo gradativamente ocupadas, assim como áreas de pasto, que se reduziram drasticamente. Apesar disso, muitos testemunhos dão conta de que as áreas de mata em fins do século XIX eram ainda de dimensões nada desprezíveis. ${ }^{48}$

Conforme nos atesta um viajante da época, grande parte destas matas estava alocada no interior das fazendas ${ }^{49}$, mormente as de açúcar, maiores consumidoras de madeira. O Engenho Central, por exemplo, no início do século XX, tinha 401,5 alqueires de florestas, 290,5 plantados com cana, 75 com café, 137,5 com pastagens, 202 estéreis e 437,5 incultas mas próprias para o cultivo. O engenho Monte Alegre, por seu lado, possuía 500 hectares de cana plantados, 250 de pastos, 622 de terras incultas e 856 de matas. Isso mostra, ainda no fim do século XIX, a importância das áreas de mata e das áreas baldias para as futuras ampliações dos canaviais. O mesmo devendo ocorrer com as fazendas de café, dada sua maior mobilidade. Por outro lado, o tempo de pousio reduziuse enormemente, em função tanto do fechamento da fronteira quanto da forte pressão demográfica que se observa no período. Mas apesar da tendência de formação de uma matriz agrícola já em fins do século XIX, a redução drástica da vegetação nativa da região seria uma história do século XX.

\section{CONCLUSÃO}

Os dados empíricos aqui trabalhados, embora estejam longe de esgotar as suas enormes possibilidades de uso, permitem concluir antes e acima de tudo que nenhuma das teorias que tratam da dinâmica das paisagens humanizadas é suficiente, se tomadas isoladamente. As mudanças de uso e cobertura da terra devem-se a múltiplos e complexos fatores, que interagem de forma dialética: a organização econômica mundial, que condiciona os modelos em uso em sua periferia; a ecologia local, que afeta os processos humanos; a demografia, condicionando os usos possíveis da terra, bem como seu estádio tecnológico; os regimes de propriedade e de uso dos fatores produtivos, condicionando os diferentes padrões de paisagem; políticas governamentais, como as que visavam controlar as áreas de plantio de café a fim de evitar sua expansão e crises nos anos 1920; e, por fim, a escala de tempo com que se trabalha, permitindo ver certas mudanças mas não outras.

O que se pode concluir, então, a respeito da paisagem de Piracicaba, por tudo o que foi dito até aqui, e com base nos dados trabalhados, é que ela correspondeu ao dinamismo próprio da história, num jogo nem sempre explícito entre mudanças e permanências, ao longo de seus cerca de trezentos anos como unidade territorial. Isto permite relativizar a ideia da existência de "áreas tradicionais" de cana e de pastagens, que supostamente estão ali do mesmo modo que sempre estiveram. 
Como visto, Piracicaba fragmentou-se enormemente, em vários sentidos. Compunha-se originalmente de $13.000 \mathrm{~km}^{2}$, hoje reduzidos a cerca de $1.300 \mathrm{~km}^{2}$. Com os desmembramentos, perdeu muito de sua diversidade paisagística inicial. Perdeu, por exemplo, as imensas áreas de campo cerrado de que se compunha quando ainda lhe pertenciam Araraquara e Rio Claro. Mas perdeu com isso também imensas áreas de pasto e depois de café.

Até a primeira metade do século XIX sua paisagem natural havia sido muito pouco alterada: os índios que habitavam suas terras não praticavam agricultura e os primeiros povoadores cultivaram-na de forma bastante modesta.

Neste período, pode-se distinguir duas paisagens bastante distintas, a dos vales e a dos espigões, nas altitudes maiores. A do vale, seguindo o curso do rio, já era relativamente antropomorfizada em meados do século XIX. Tanto a agricultura de subsistência quanto a comercial havia crescido de forma significativa, acompanhando o ritmo de crescimento da população. A dos espigões mantinha ainda sua feição original, pois só seria alterada com a introdução do café. O milho, ao lado da cana, dominava a maior parte da paisagem rural.

Piracicaba era composta, originalmente, de vastas áreas de mata, do tipo "Catanduva", conforme designação de época, recortadas por campos em diversos estágios de sucessão, bem como por culturas de milho, feijão, arroz, mandioca e cana. A dinâmica agrícola em uso impôs um processo de ocupação muito peculiar. Devido ao baixo nível tecnológico, decorrente da instituição da escravidão, os agricultores preferiam ocupar as áreas de mata, supostamente com solos mais férteis do que as áreas de campo. Além disso, as fazendas de cana necessitavam da madeira das matas para suas atividades ordinárias. Isso permitiu manter as áreas de campo, bem como as de mata, praticamente intocadas até o fim do século XIX. Apenas com o aumento da pressão demográfica sobre áreas de fronteira, é que as áreas de campo passarão a ser ocupadas por atividades agrícolas.

Por seu lado, o uso do pousio longo ou do arbustivo, no início do povoamento, permitiu manter por mais tempo a fisionomia da vegetação original. Apesar do que foi possível concluir a respeito da composição original, fica difícil de precisar a localização exata dos diferentes tipos de formação vegetal da região, já que muitas áreas incultas do passado se confundem entre "carrascal" e cerrado.

Por esta época, tendia a predominar em sua paisagem rural a grande propriedade, apesar de suas nítidas diferenças em relação às imensas propriedades do litoral nordestino do período colonial. A partir já de meados do século XIX, observa-se uma tendência de retalhamento da propriedade rural, o que mudará completamente a paisagem da região na segunda metade do século. Contribui para esta mudança a introdução do café, que, como visto, não substitui a cana, nem mesmo as culturas alimentares, apesar de seu relativo encolhimento neste período. Tendo se concentrado, sobretudo, nos espigões, 
não se pode dizer ter sido ele o responsável pela eliminação das formações vegetais da bacia do Corumbataí, incluída na folha de Piracicaba. ${ }^{50}$

Então, o que se vê em fins do século XIX é uma paisagem bastante diversa, humana como natural. Unidades rurais menores e mais cultivadas, agora também nos espigões; áreas de cerrado divididas entre vegetação nativa, pasto para animais e culturas alimentares. Mas as áreas de mata do interior das fazendas, que são a maioria, mantêm-se ainda quase intactas, muito similar, neste sentido, a sua matriz original.

Os cafezais, por sua mobilidade maior que a da cana, contribuíram muito para o avanço da paisagem agrária e o encolhimento da vegetação nativa. Mas apesar dessa memória do café, simultaneamente ligada ao povoamento e ao progresso da região, mas também à destruição de sua vegetação, a verdade é que foi a cana uma realidade permanente da paisagem piracicabana. Apesar disso, sua permanência não se fez sem mudança, pois, como visto, ela se deslocou bastante dentro do espaço que lhe era possível ocupar. Enquanto o café tendeu a encolher-se a partir dos anos 1920, em função das crises de superprodução e de retração da demanda mundial, acompanhado neste sentido pelas culturas alimentares, a cana só fez expandir-se, em função do aumento da demanda interna e dos avanços técnicos na área do fabrico de açúcar. E na medida em que avançava, mormente no tempo das modernas usinas, onde já não eram necessárias as reservas de matas, a vegetação natural ia se encolhendo. Este processo se intensificaria, sobretudo, a partir dos anos 1960, quando já quase nada restava da Piracicaba original.

As áreas incultas também foram sendo gradativamente incorporadas à paisagem da cana, assim como as áreas voltadas ao reflorestamento. A esta altura, final do século XX, as áreas de cerrado, bem como as de culturas alimentares, reduziram-se a quase nada. Quanto à tendência de fragmentação da propriedade fundiária, ela já havia se invertido desde o início do século XX. De modo que o padrão predominante hoje, muito distinto daquele de há um século atrás, é de grandes unidades monocultoras. Ironicamente, o mesmo de há três séculos no Nordeste colonial e que se impôs à memória coletiva.

\section{NOTAS}

${ }^{1}$ SPAROVEK, Gerd. Atlas rural de Piracicaba. Piracicaba: IPEF, 2006.

${ }^{2}$ Os paiaguás representaram uma forte resistência ao processo de colonização da região, só sendo derrotados em 1733, quando partiu de São Paulo uma expedição armada organizada pelo capitão geral Antonio Luiz da Távora, comandada por Gabriel Antunes Maciel e composta por considerável número de posseiros já estabelecidos em Piracicaba.

${ }^{3}$ PERRONE-MOISÉS, Beatriz. Índios livres e índios escravos. In: CUNHA, Manuela Carneiro da (Org.). História dos índios no Brasil. São Paulo: Companhia das Letras, 1992; CAMARGO, Manoel de. Almanaque de Piracicaba para o ano de 1900. São Paulo: Typ. Hermes \& Irmãos, 1899. 
${ }^{4}$ A colônia militar de Iguatemi foi criada com o intuito de guardar a fronteira com o Paraguai. Os relatos existentes informam que quando ela foi fechada, em 1775, a lavoura de Piracicaba sofreu forte retração.

${ }^{5}$ TAUNAY, Affonso de E. Relatos monçoeiros. São Paulo: Martins, 1976. p. 227.

${ }^{6}$ ALMEIDA, Francisco José de Lacerda e. Diários de viagem. Rio de Janeiro: Imprensa Nacional, 1944. p. 107; TORRES, Maria Celestina Teixeira Mendes. Piracicaba no século XIX. Piracicaba: Degaspari, 2003.

${ }^{7}$ LEANDRO, Luiz (Org.). Subsídios para a história de Piracicaba. Piracicaba: Editora Jornal de Piracicaba, 1961; Representação ao governo da Província, 1816; RAMOS, Pedro. História econômica de Piracicaba (1765-1930). In: TERCI, Eliana Tadeu (Org.). O desenvolvimento de Piracicaba: história e perspectivas. Piracicaba: Unimep, 2001.

${ }^{8}$ TORRES, Maria Celestina Teixeira Mendes. Aspectos da evolução da propriedade rural em Piracicaba - no tempo do Império. Piracicaba: Academia Piracicabana de Letras, 1975; CAMARGO, op. cit.; FORJAZ, Djalma. Senador Vergueiro, sua vida e sua época (1778-1859). São Paulo: Officinas do Diario Official, 1924. p. 23-28.

${ }^{9}$ TSCHUDI, J. J. Viagem às províncias do Rio de Janeiro e São Paulo. São Paulo: Edusp, 1980.

${ }^{10}$ BARTHELMESS, Heloisa. A zona de Piracicaba. Curitiba: Universidade do Paraná, 1958; TSCHUDI, op. cit.; ZALUAR, Augusto Emílio. Peregrinação pela província de São Paulo (1860-1861). São Paulo: Edusp, s.d.; LIMA, Sebastião Nogueira de. Piracicaba de 1860, Jornal de Piracicaba, 26 abr. 1938.

${ }^{11}$ SAINT-HILAIRE, Auguste de. Viagem à província de São Paulo. São Paulo: Edusp, 1976. p. 56.

${ }^{12} \mathrm{O}$ termo "Catanduva", que depois daria origem ao nome da atual cidade do interior paulista, se origina das palavras tupis caá, mata, e ahiva, ruim. Daí esse tipo de vegetação ser chamado também de "mata ruim", devido ao suposto baixo valor nutricional de suas terras, o que as tornaria imprópria para a agricultura.

${ }^{13}$ LUND, Peter W. Memórias scientificas. Belo Horizonte: Biblioteca Mineira de Cultura, 1935.

${ }^{14}$ TAUNAY, op. cit., p. 228.

${ }^{15}$ BRUNO, Ernani da Silva. Viagem ao país dos paulistas. Rio de Janeiro: José Olympio, 1966.

${ }^{16}$ A tese mais conhecida neste sentido é a da geógrafa Heloisa Barthelmess (1958: 56), para quem "o simples fato de ser a economia da zona de Piracicaba predominantemente agrícola desde os primórdios de sua ocupação humana já constitui por si só forte indício de tratar-se de região originariamente florestal".

${ }^{17}$ SAINT-HILAIRE, op. cit., p. 96.

${ }^{18}$ O termo era usado por Saint-Hilaire para designar "as pequenas matas esparsas pelos campos". SAINT-HILAIRE, op. cit., p. 98.

${ }^{19}$ FLORENCE, Hercules. De Porto Feliz a Cuiabá. Diário de viagem de um naturalista da expedição do Barão de Langsdorff em 1826 e 1827. São Paulo: Diário Official, 1929. p. 34.

${ }^{20}$ Ibidem, p. 50.

${ }^{21}$ A expedição de Martim Afonso de Souza, que chega ao Brasil em 1532, trouxe consigo mudas de cana, bem como peritos na manufatura do açúcar.

${ }^{22}$ PRADO JUNIOR, Caio. Formação do Brasil contemporâneo. São Paulo: Brasiliense, 1996. 
${ }^{23}$ HOLANDA, Sérgio Buarque de. Raízes do Brasil. São Paulo: Companhia das Letras, 1996; HOLANDA, Sérgio Buarque de. Visão do paraiso. São Paulo: Brasiliense/Publifolha, 2000.

${ }^{24} \mathrm{O}$ fornecimento de lenha para um engenho era algo extremamente crítico. Há relatos na bibliografia sobre engenhos que deixaram de funcionar por falta desta matéria prima (ENGEMANN, C. et al. Consumo de recursos florestais e produção de açúcar no período colonial: o caso do engenho do Camorim, RJ. In: OLIVEIRA, R. R. (Org.). As marcas do homem na floresta: história ambiental de um trecho urbano de Mata Atlântica. Rio de Janeiro: Editora PUC-RJ, 2005. p. 119-142).

${ }^{25}$ CANABRAVA, Alice P. A grande lavoura. In: HOLANDA, Sérgio Buarque de. História geral da civilização brasileira. Rio de Janeiro: Difusão Européia do Livro, 1972.

${ }^{26}$ Isto é, São Vicente teve o primeiro engenho do Brasil, na década de 1530.

${ }^{27}$ PETRONE, Maria Thereza Schorer. O desprezado ciclo do açúcar paulista. In: ODALIA, Nilo; CALDEIRA, João R. C. (Orgs.). História do Estado de São Paulo. São Paulo: Editora da UNESP, 2010. p. 138-141.

${ }^{28}$ MELLO, Joaquim Silveira. A estrada do picadão de Cuiabá a Piracicaba, 1836-1840, Jornal de Piracicaba, 27, 28, 30 nov. 1915; 01 dez. 1915; 5, 6, 8, 11 jan. 1916.

${ }^{29}$ Um estudo sobre a acumulação de capital na região de Piracicaba no século XIX começou a ser feito por uma aluna da graduação e sua conclusão, prevista para daqui há dois anos, deverá contribuir muito para o esclarecimento do problema.

${ }^{30}$ APESP, Lista nominal de população, maço/população de Piracicaba; MÜLLER, Daniel Pedro. Ensaio d'um quadro estatístico da província de São Paulo. São Paulo: O Estado de S. Paulo, 1923; ESTADO DE SÃO PAULO. Quadro estatístico da população da província de São Paulo recenseado no ano de 1854. In: Documentos com que o Ilustríssimo e Excelentíssimo Sr. Dr. José Antônio Saraiva presidente da Província de S. Paulo instruiu o relatório da abertura da Assembléia Legislativa provincial no dia 15 de fevereiro de 1855. São Paulo: Typographia Dous de Dezembro de Antonio Louzada Antunes, 1855.

${ }^{31}$ BRANDÃO SOBRINHO, Julio (Org.). Almanaque ilustrado do lavrador paulista. São Paulo: Duprat \& Comp., 1905. p. 191-194.

${ }^{32}$ TORRES, op. cit.

${ }^{33}$ TAUNAY, Carlos Augusto. Manual do agricultor brasileiro. São Paulo: Companhia das Letras, 2001.

${ }^{34}$ TORRES, op. cit.; MÜLLER, op. cit.

${ }^{35}$ POHL, Johann E. Viagem no interior do Brasil. Belo Horizonte: Itatiaia, 1976.

${ }^{36}$ TORRES, op. cit., p. 60.

${ }^{37}$ Anuário Estatístico do Estado de São Paulo, 1893-1918.

${ }^{38}$ MÜLLER, op. cit.

${ }^{39}$ DIRETORIA GERAL DE ESTATÍSTICA, Recenseamento do ano de 1890.

${ }^{40}$ Quadro estatístico da população da província de São Paulo recenseada no ano de 1854, op. cit.; Lista Nominal do Arquivo Público do Estado de São Paulo, op. cit.; COMISSÃO CENTRAL DE ESTATÍSTICA, Recenseamento Geral do Império, 1872; COMISSÃO CENTRAL DE ESTATÍSTICA, Relatório para o ano de 1886.

${ }^{41}$ TAUNAY, op. cit., p. 122-123. 
${ }^{42}$ Ibidem, p. 124.

${ }^{43}$ PÁDUA, José Augusto. Um sopro de destruição. Rio de Janeiro: Jorge Zahar, 2004.

${ }^{44}$ TAUNAY, op. cit., p. 126.

${ }^{45}$ RAMOS, op. cit.; PETRONE, op. cit.

${ }^{46}$ Anuário Estatístico do Estado de SP, 1893-1918; DIRETORIA GERAL DE ESTATÍSTICA, op. cit.; Quadro estatístico da população da província de São Paulo recenseada no ano de 1854, op. cit.

${ }^{47}$ BARROS, Manoel de Morais. O município e a cidade de Piracicaba, Gazeta de Piracicaba, 21, 23 e 26 set. 1883.

${ }^{48}$ CAMARGO, op. cit., p. 139.

${ }^{49}$ ZALUAR, op. cit., p. 150.

${ }^{50}$ SPAROVEK, op. cit.

Artigo recebido em março de 2013. Aceito em agosto de 2013. 